\title{
Zero-valent iron supported-lemon derived biochar for ultra-fast adsorption of methylene blue
}

\author{
Eman M. Abd El-Monaem ${ }^{1} \cdot$ Ahmed M. Omer ${ }^{2} \cdot$ Gehan M. El-Subruiti ${ }^{1} \cdot$ Mohamed S. Mohy-Eldin ${ }^{2}$. \\ Abdelazeem S. Eltaweil ${ }^{1}$
}

Received: 5 November 2021 / Revised: 15 January 2022 / Accepted: 18 January 2022

(c) The Author(s) 2022

\begin{abstract}
Green-based materials represent a new promising class of ecofriendly and economic adsorbents. Herein, nano zero-valent iron supported-lemon derived biochar (NZVI-LBC) was prepared for the first time and examined in the adsorptive removal of methylene blue as a model pollutant. Different characterization tools were used to ensure the successful fabrication of the NZVI-LBC composite including FTIR, XRD, TEM, XPS, VSM, BET, and zeta potential analysis. It was found that the fabricated NZVI-supported biochar composite attained the propitious adsorbent criteria since it provided a supreme efficient adsorption process at short time. The reckoned maximum adsorption capacity of MB onto NZVI-LBC reached $1959.94 \mathrm{mg} / \mathrm{g}$ within merely $5 \mathrm{~min}$. The obtained data clarified that the adsorption process of MB onto NZVI-LBC fitted pseudo $2^{\text {nd }}$ order kinetic model and Freundlich isotherm model. Besides, the adsorption process of MB onto NZVI-LBC was found to be endothermic in nature. In addition, NZVI-LBC composite revealed an excellent adsorption behavior even after seven cycles. The concrete results reflect the potentiality of NZVI-LBC composite to be a superb candidate to remove cationic pollutants from their aqueous solutions.
\end{abstract}

Keywords Biochar $\cdot$ NZVI $\cdot$ Methylene blue $\cdot$ Removal $\cdot$ Magnetic $\cdot$ Lemon residue

\section{Introduction}

Water pollution is the most enormous environmental dilemma that is rising swiftly day-by-day. As a result, myriad diseases have aggravated such as typhoid, hepatitis, and cancer since the polluted water directly affects human health [1-3]. Thence, researchers have exerted arduous efforts, pursuing crucial solutions to get rid of these fatal pollutants and fulfill safe drinking water [4]. Among these troublesome contaminants, methylene blue (MB) is the most pervasive

Eman M. Abd El-Monaem

emanabdelmonaem5925@yahoo.com

$\triangle$ Abdelazeem S. Eltaweil

abdelazeemeltaweil@alexu.edu.eg

1 Chemistry Department, Faculty of Science, Alexandria University, Alexandria 21321, Egypt

2 Polymer Materials Research Department, Advanced Technology and New Materials Research Institute (ATNMRI), City of Scientific Research and Technological Applications (SRTA-City), New Borg El-Arab City 21934, Alexandria, Egypt synthetic dyes in diversified potential industries such as food, paper, plastic, leather, and textile [5, 6]. Nevertheless, MB causes vast apprehensions on human health and our environment entirely. It was found that the existence of MB into water bodies even with minimal concentration has severe influences on human health including blood pressure, gastrointestinal pain, vomiting, headache, and irritation of throat [7, 8]. Hence, advanced techniques have evolved to face these catastrophic risks of MB such as electrolysis [9], catalytic reduction [10], photocatalysis [11-13], membrane separation [14], chemical oxidation [15], and particularly adsorption since it is quite simple, highly efficient, and costless techniques [16-18].

Biochar (BC) is a dusty carbonaceous compound that is produced via thermochemical decomposition of diverse and bountiful bio-wastes [19-23]. BC has received vast consideration as a promising adsorbent owing to its appreciable characteristics including porous structure, huge specific surface area, high mechanical strength, and plenty of oxygenated functional groups (i.e., carboxylic and phenolic) [24, 25]. Furthermore, recycling bio-wastes especially the agriculture crop residuals instead of burning them is considered 
as the best of the best solution in terms of human health [26-28]. Several studies investigated that burning these crop residuals directly intensifies the suspended particulate matter, the main responsible for different respiratory diseases. Nonetheless, BC has a significant drawback which is a limited capacity to adsorb contaminants from aqueous media [29]. It was investigated that combining BC with magnetic nanomaterials is a feasible solution to overcome this flaw as well as it provides easy separation and good recyclability for $\mathrm{BC}$.

NZVI is one of the most popular magnetic nanoparticle for wastewater treatment due to its incomparable properties including high specific surface area, excellent adsorption property, high surface energy, and strong reducing ability $[30,31]$. However, NZVI suffers many flaws including aggregation, poor transportability, and reduced electron transfer [32]. So, diversified approaches have been implemented to get rid of these demerits such as using surfactants [33] and forming a composite to isolate the surface of NZVI particles, protecting them from exposure to air [34]. It was reported in related studies that NZVI-modified BC nanocomposite is a propitious candidate for the adsorptive removal of miscellaneous contaminants such as organic dye [35, 36], nitroaromatic compound [37], and heavy metals [38]. Essentially, this combination has a dual benefit since BC enhances the dispersion of the magnetic NZVI particles and inhibits their aggregation [39]. Thence, BC endows NZVI more stability in air with low aggregation, retaining its good adsorption and reduction properties [40]. On the other hand, NZVI ameliorates the adsorption capability of BC, as well as their magnetic behavior, and facilitates the separation by an external magnet rather than centrifugation and filtration techniques that are less efficient and consume longer time [41].

Herein, we adopted the concept of fabricating a low-cost and ecofriendly adsorbent possessing extraordinary fast and super-adsorption capability. To the best of our knowledge, this is the first time to fabricate NZVI-supported lemonderived biochar composite. A complete characterization of the fabricated NZVI-LBC magnetic nanocomposite was performed. Moreover, the fabricated NZVI-LBC nanocomposite was tested for the selective removal of MB.

\section{Experimental section}

\subsection{Materials}

Lemon residues were collected from a juice shop in Alexandria, Egypt. Ferric chloride hexahydrate $\left(\mathrm{FeCl}_{3} \cdot 6 \mathrm{H}_{2} \mathrm{O}\right.$, 99\%) was supplied from Alpha Chemika (India). Sodium borohydride $\left(\mathrm{NaBH}_{4}, 98.7 \%\right)$ and ethanol $\left(\mathrm{C}_{2} \mathrm{H}_{5} \mathrm{OH}, 99 \%\right)$ were bought from Rankem (India). MB was obtained from MP Biomedicals, LLC (France).

\subsection{Preparation of NZVI-LBC nanocomposite}

Firstly, lemon residues were well washed with distilled water, then dried in an oven at $100{ }^{\circ} \mathrm{C}$ for $12 \mathrm{~h}$. The formed crunchy lemon residues were grinded by a blender; afterwards, the obtained fine powder was carbonized in a muffle furnace at $500{ }^{\circ} \mathrm{C}$ for $5 \mathrm{~h}$ under oxygen-limited conditions since the crucible was put into a stainless steel cylinder. The air in the cylinder was removed by $\mathrm{N}_{2}$ gas to infer an oxygen-free atmosphere. Then, the cylinder was put into the furnace. Secondly, $0.1 \mathrm{~g} \mathrm{LBC}$ and $0.35 \mathrm{~g} \mathrm{FeCl}_{3} \cdot 6 \mathrm{H}_{2} \mathrm{O}$ were dispersed in $20 \mathrm{ml}$ ethanol for $15 \mathrm{~min}$. Then after, freshly prepared $\mathrm{NaBH}_{4}$ solution $(33 \mathrm{ml}, 0.1 \mathrm{M})$ was added to the reaction mixture drop by drop under robust stirring. Ultimately, the black powder was separated by an external magnet, washed with ethanol, and dried under vacuum at $50{ }^{\circ} \mathrm{C}$ for $3 \mathrm{~h}$.

\subsection{Characterization tools}

For in-depth study of the as-fabricated NZVI-LBC nanocomposite, various characterization tools were utilized including transmission electron microscope (TEM, JEOL-2100 plus) to investigate the surface morphology. The TEM sample was prepared by sonicating $5 \mathrm{mg}$ of the NZVI-LBC composite into $10 \mathrm{ml}$ of ethanol for $3 \mathrm{~h}$. Then after, a few drops of the resulting suspension were put onto a grid coated with copper. Moreover, $\mathrm{N}_{2}$ adsorption-desorption isotherm was performed to estimate the BET adsorption isotherm (BET, Beckman coulter) after the sample was degassed for $1 \mathrm{~h}$ at $250{ }^{\circ} \mathrm{C}$, and the specific surface area was determined by plotting BET equation at $\mathrm{P} / \mathrm{P}_{0}$ in the range from 0.01 to 0.35 . The chemical composition was inspected by Fourier transform infrared spectra (FTIR, Tensor II, Bruker) at a wavenumber range $4000-400 \mathrm{~cm}^{-1}$. The elemental analysis was determined by X-ray photoelectron spectroscopy (XPS, Thermo Fisher Scientific). Besides, the magnetic property was measured by vibrating sample magnetometer (VSM, Lake shore). In addition, the surface charge was detected by zeta potential (ZP, Malvern). The ZP sample was prepared by dispersing $1 \mathrm{mg}$ of the NZVI-LBC composite into $10 \mathrm{ml}$ of distilled water, then $\mathrm{pH}$ was adjusted by $0.01 \mathrm{M} \mathrm{HCL}$ and/or $\mathrm{NaOH}$. Then, the suspension was sonicated for $1 \mathrm{~h}$ and injected into the cell of the instrument. Crystallite phase was scrutinized by X-ray diffraction (XRD, BRUKER D8 Advance $\mathrm{Cu}$ target) with wavelength $\lambda=1.54 \mathrm{~A}^{\circ}(\mathrm{CuK} \alpha)$, at a tube voltage of $35 \mathrm{kV}$ and tube current of $30 \mathrm{~mA}$. 
Fig. 1 XRD of LBC, NZVI, and NZVI-LBC nanocomposite (A), and FTIR of LBC, NZVI, and NZVI-LBC nanocomposite (B)
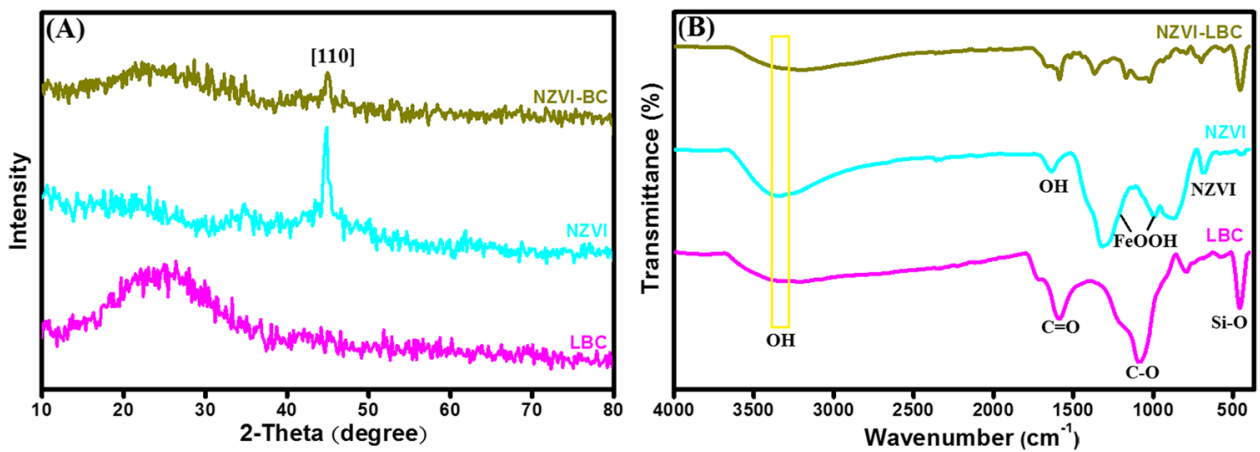

\subsection{Batch adsorption}

The adsorption capacity of the as-synthesized NZVI-LBC nanocomposite towards $\mathrm{MB}$ was scrutinized in a simple batch adsorption mode as follows: $10 \mathrm{mg}$ NZVI-LBC nanocomposite was soaked in $20 \mathrm{ml} \mathrm{MB}$ with an initial concentration range 500-2000 mg/L. The impact of $\mathrm{pH}$ on the adsorption efficiency of $\mathrm{MB}$ was assessed in $\mathrm{pH}$ range $3-11$, where $\mathrm{pH}$ of the contaminant solutions was adjusted by $0.1 \mathrm{M} \mathrm{NaOH}$ and/or $\mathrm{HCl}$. For inspecting the impact of NZVI-LBC nanocomposite dose, the adsorption of MB was studied using various composite dosages ranging from 0.005 to $0.025 \mathrm{~g}$. In addition, the impact of temperature on the adsorption process of MB was evaluated at a temperature range $25-55^{\circ} \mathrm{C}$. Finally, the contaminant residual concentration was tested by utilizing spectrophotometer at $\lambda_{\max }=664 \mathrm{~nm}$. Finally, the removal efficiency $(\mathrm{R} \%)$ and the adsorption capacity (q) were calculated by Eqs. 1 and 2:

$\mathrm{R} \%=\frac{\mathrm{C}_{0}-\mathrm{C}_{\mathrm{t}}}{\mathrm{C}_{0}} \times 100$

$q=\frac{\left(C_{0}-C_{t}\right) \times V}{m}$

where $C_{o}$ and $C_{t}$ are the initial concentration and the concentration of $\mathrm{MB}$ at certain time, respectively. $m$ is the mass of NZVI-LBC nanocomposite and $V$ is the volume of MB solution, respectively.

\subsection{Selectivity study}

The selectivity of NZVI-LBC nanocomposite was examined in the presence of the cationic crystal violet (CV) and the anionic Congo red (CR) in a dye mixture binary system (MB-CV) and (MB-CR) and ternary system (MB-CR$\mathrm{CV})$. The test is carried out as follows: $0.01 \mathrm{~g}$ NZVI-LBC nanocomposite was added to $20 \mathrm{ml}$ multi-dye solution, then NZVI-LBC was collected by an external magnet, and the concentration of residual dyes was measured via spectrophotometer $\left(\lambda_{\max }(\mathrm{CR})=500 \mathrm{~nm}\right.$ and $\left.\lambda_{\max }(\mathrm{CV})=598 \mathrm{~nm}\right)$.

\subsection{Desorption study}

The significant merit of any adsorbent such as low cost, ecofriendly, or even excellent adsorption property is useless if the adsorbent has poor reusability. Accordingly, it was a pivotal issue to attest the reusability of the as-synthesized NZVI-LBC nanocomposite. The reusability test was executed as follows: the magnetic NZVI-LBC nanocomposite was collected by an external magnet after each adsorption cycle $\left(\mathrm{V}=20 \mathrm{~mL}, \mathrm{C}_{0}=500 \mathrm{mg} / \mathrm{L}\right.$ and adsorbent dose $0.01 \mathrm{~g}$ ), washed with ethanol, and reused in the next cycle.

\section{Results and discussion}

\subsection{Investigation of the properties of the as-fabricated NZVI-LBC nanocomposite}

\subsubsection{XRD}

Figure 1A clarifies the crystal phase of LBC, NZVI, and NZVI-LBC nanocomposite. For LBC, XRD spectrum signifies the amorphous phase of the as-synthesized LBC. Moreover, XRD of NZVI points out its characteristic peak at $2 \theta=44.8^{\circ}$ which is the fingerprint of body-centered cubic NZVI [42], whereas XRD spectrum of NZVI-LBC nanocomposite elucidates the distinguishing peak of NZVI with lower intensity than the pristine NZVI, reflecting the successful incorporation of NZVI into LBC [40].

\subsubsection{FTIR}

FTIR spectra of LBC, NZVI, and NZVI-LBC nanocomposite exhibit (Fig. 1B) broad band around $3300 \mathrm{~cm}^{-1}$ which is ascribed to $\mathrm{OH}$ vibration stretching. FTIR spectrum of LBC displays the two peaks at 795 and $1592 \mathrm{~cm}^{-1}$ which are attributed to $\mathrm{C}-\mathrm{H}$ and $\mathrm{C}=\mathrm{C}$ of the aromatic ring, respectively [43]. Besides, the peak at $457 \mathrm{~cm}^{-1}$ belongs to $\mathrm{Si}-\mathrm{O}$ and the peak at $1086 \mathrm{~cm}^{-1}$ relates to $\mathrm{C}-\mathrm{O}$ of ester [44]. Moreover, FTIR of NZVI reveals the belonging peak to NZVI at $680 \mathrm{~cm}^{-1}$, while the two peaks at 995 
Fig.2 XPS of NZVI-LBC nanocomposite; spectrum survey (A), Fe2p (B), C1s (C), and O1s (D)
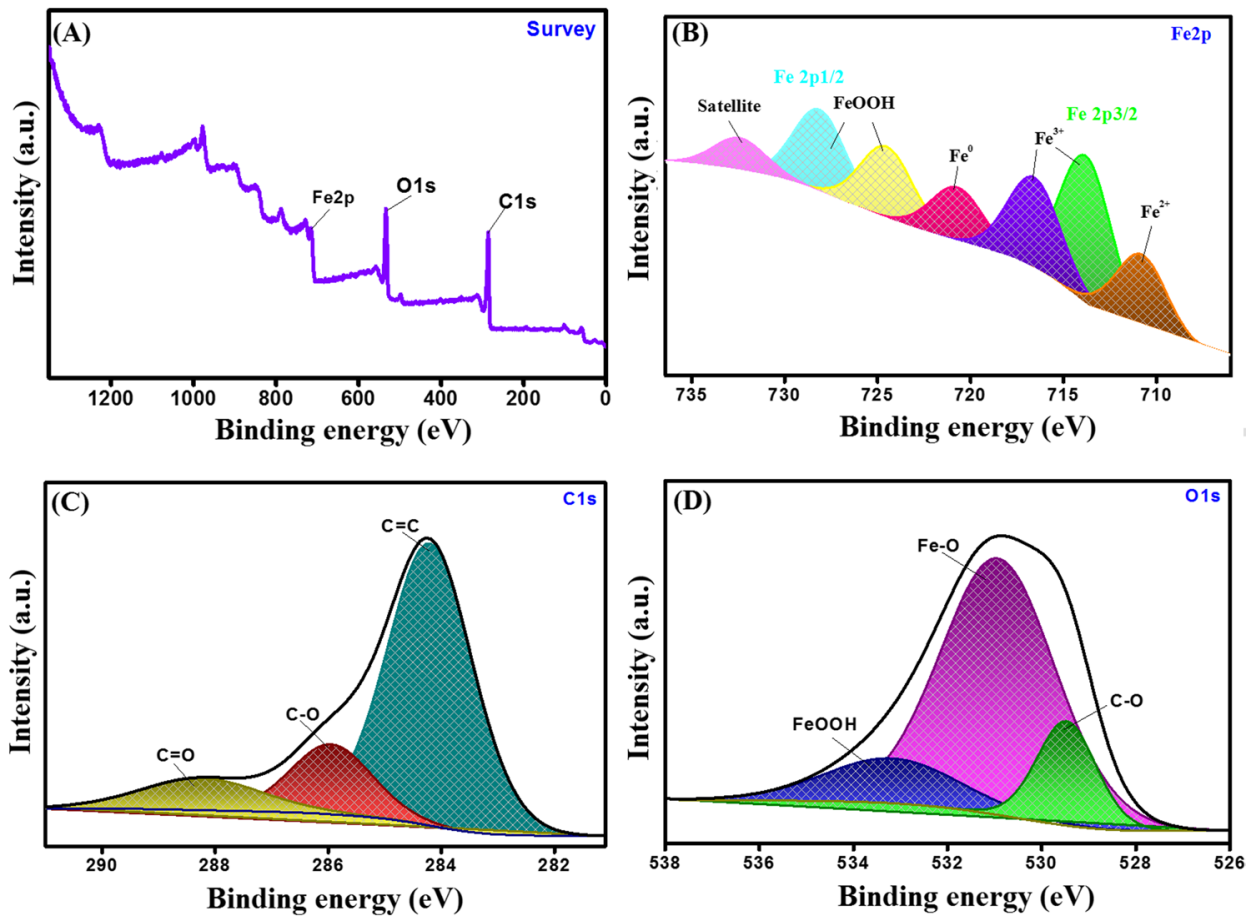

and $1320 \mathrm{~cm}^{-1}$ are corresponded to $\mathrm{FeOOH}$, evincing the core-shell structure of NZVI [45]. In addition, the peak at $1600 \mathrm{~cm}^{-1}$ is ascribed to $\mathrm{OH}$ binding and the peaks at 459 and $685 \mathrm{~cm}^{-1}$ are assigned to $\mathrm{Fe}-\mathrm{O}$ stretching vibration [30, 46]. FTIR spectrum of NZVI-LBC nanocomposite clarifies the discriminative peaks of both LBC and NZVI but with low peak intensities.

\subsubsection{XPS}

XPS spectra signalize the successful fabrication of NZVILBC nanocomposite since the survey spectrum (Fig. 2A) illustrates the main elements of the nanocomposite: Fe2p, C1s, and O1s. For Fe2p spectrum (Fig. 2B), $\mathrm{Fe}^{2+}$ appeared at $\mathrm{BE}$ of $710.85 \mathrm{eV}$, while the two peaks emerged at $\mathrm{BE}$ of 713.97 and $716.74 \mathrm{eV}$ correspond to $\mathrm{Fe}^{3+}$ [47]. Essentially, the presence of $\mathrm{Fe}^{0}$ indicated by the peak at $\mathrm{BE}$ of 720.81 and the existence of $\mathrm{FeOOH}$ at BE of 724.66 and $728.34 \mathrm{eV}$ infers the suggested core-shell structure of NZVI [48]. Moreover, C1s spectrum (Fig. 2C) points out the peaks at $\mathrm{BE}$ of $288.35,285.96$, and $284.19 \mathrm{eV}$ which are ascribed to $\mathrm{C}=\mathrm{O}, \mathrm{C}-\mathrm{O}$, and $\mathrm{C}=\mathrm{C}$, respectively [49]. Furthermore, O1s spectrum (Fig. 2D) clarifies the corresponding peaks to $\mathrm{FeOOH}, \mathrm{Fe}-\mathrm{O}$, and $\mathrm{C}-\mathrm{O}$ at $\mathrm{BE}$ of $529.99,530.96$, and $533.25 \mathrm{eV}$, respectively [42].

\subsubsection{TEM}

TEM image of NZVI (Fig. 3A) points out a great aggregation of the particles owing to their high magnetism.
Furthermore, Fig. 3B infers the distinctive core-shell structure of NZVI that is ascribed to the oxidation or corrosion of $\mathrm{Fe}^{0}$ due to the existence of water and oxygen during the fabrication process, resulting in the formation of iron oxide shell surrounding the surface of $\mathrm{Fe}^{0}$ [50]. On the other hand, TEM images of NZVI-LBC nanocomposite (Fig. 3C, D) clarify the well-dispersion of the particles since the presence of LBC dwindles the magnetism of NZVI, resulting in diminishes the aggregation of the particles [42].

\subsubsection{VSM}

To assert the TEM observation, the magnetism of pure NZVI and NZVI-LBC nanocomposite was inspected by VSM. Figure 4A points out that the saturation magnetization of NZVI decreased almost to its half (from 72.50 to $39.36 \mathrm{emu} / \mathrm{g}$ ) after the combination with the non-magnetic LBC. Furthermore, it was found that the coercivity values of NZVI and NZVI-LBC is larger than $20 \mathrm{G}$, indicating the soft ferromagnetic behavior of both samples.

\subsubsection{Zeta potential}

In general, electrostatic interaction is almost the dominant mechanism of the adsorption of most contaminants. Therefore, it is crucial to determine the surface charge of NZVI-LBC nanocomposite. Figure 4B shows the point of zero charges (PZC) of NZVI-LBC at $\mathrm{pH}$ 3.5, reflecting a favorability of NZVI-LBC to adsorb the cationic contaminants such as $\mathrm{MB}$ at $\mathrm{pH}>3.5$ owing to 
Fig. 3 TEM images of NZVI $(\mathbf{A}, \mathbf{B})$ and NZVI-LBC nanocomposite $(\mathbf{C}, \mathbf{D})$
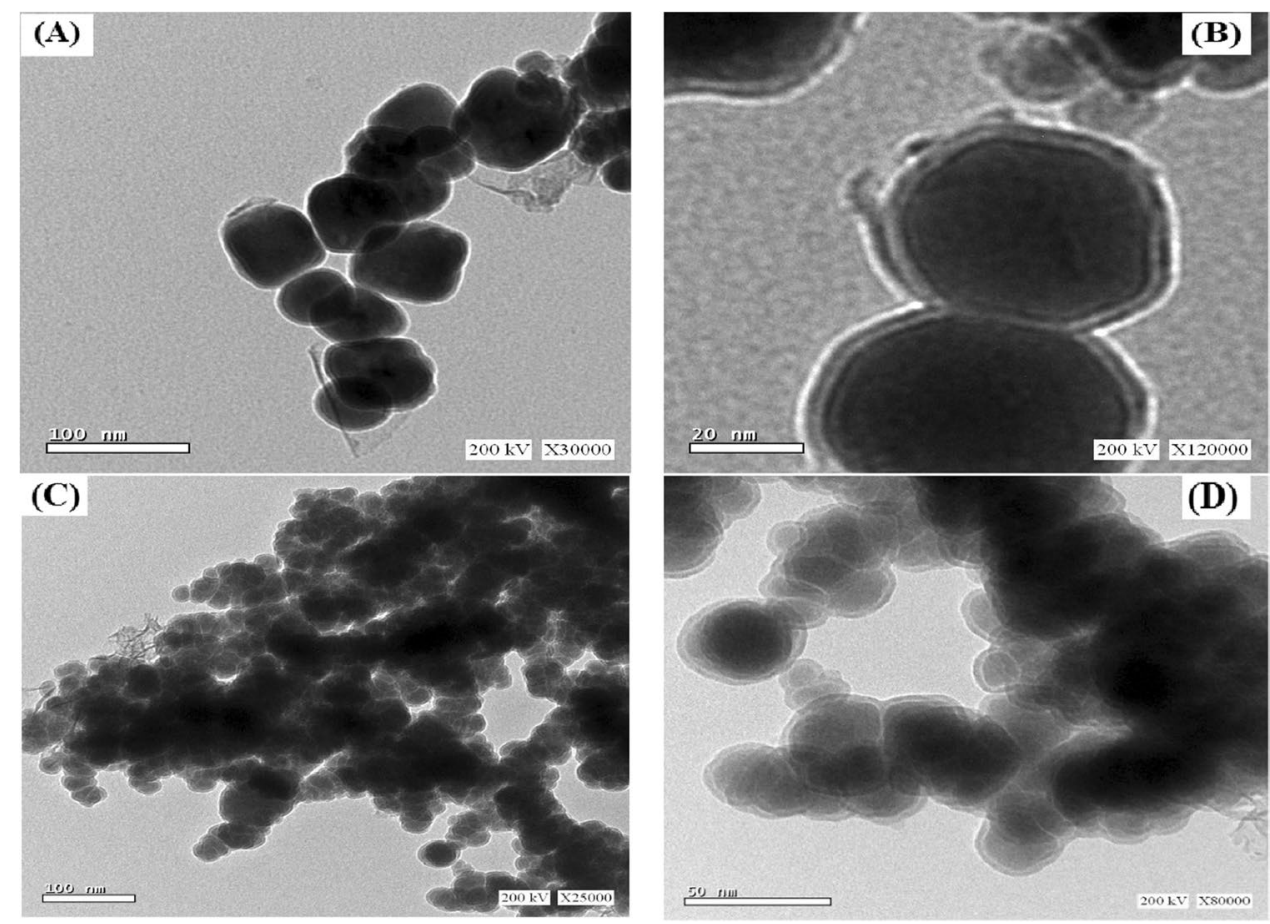

the abundance of negative charges onto its surface that spontaneously attract the positive MB molecules. Contrariwise, at $\mathrm{pH}<3.5$, the surface of NZVI-LBC is loaded with positive charges, resulting in electrostatic repulsion between the positive MB molecules and the positively charged NZVI-LBC.

\subsubsection{Textural properties}

Figure $4 \mathrm{C}$ represents the $\mathrm{N}_{2}$ adsorption/desorption isotherms of NZVI and NZVI-LBC nanocomposite. It is apparent from the isotherms that both NZVI and NZVI-LBC exhibit type II. Furthermore, the specific surface area $\left(\mathrm{S}_{\mathrm{BET}}\right)$ of
Fig. 4 VSM of NZVI and NZNI-LBC (A), ZP of NZNILBC $(\mathbf{B})$, and BET of NZVI, LBC, and NZNI-LBC (C)
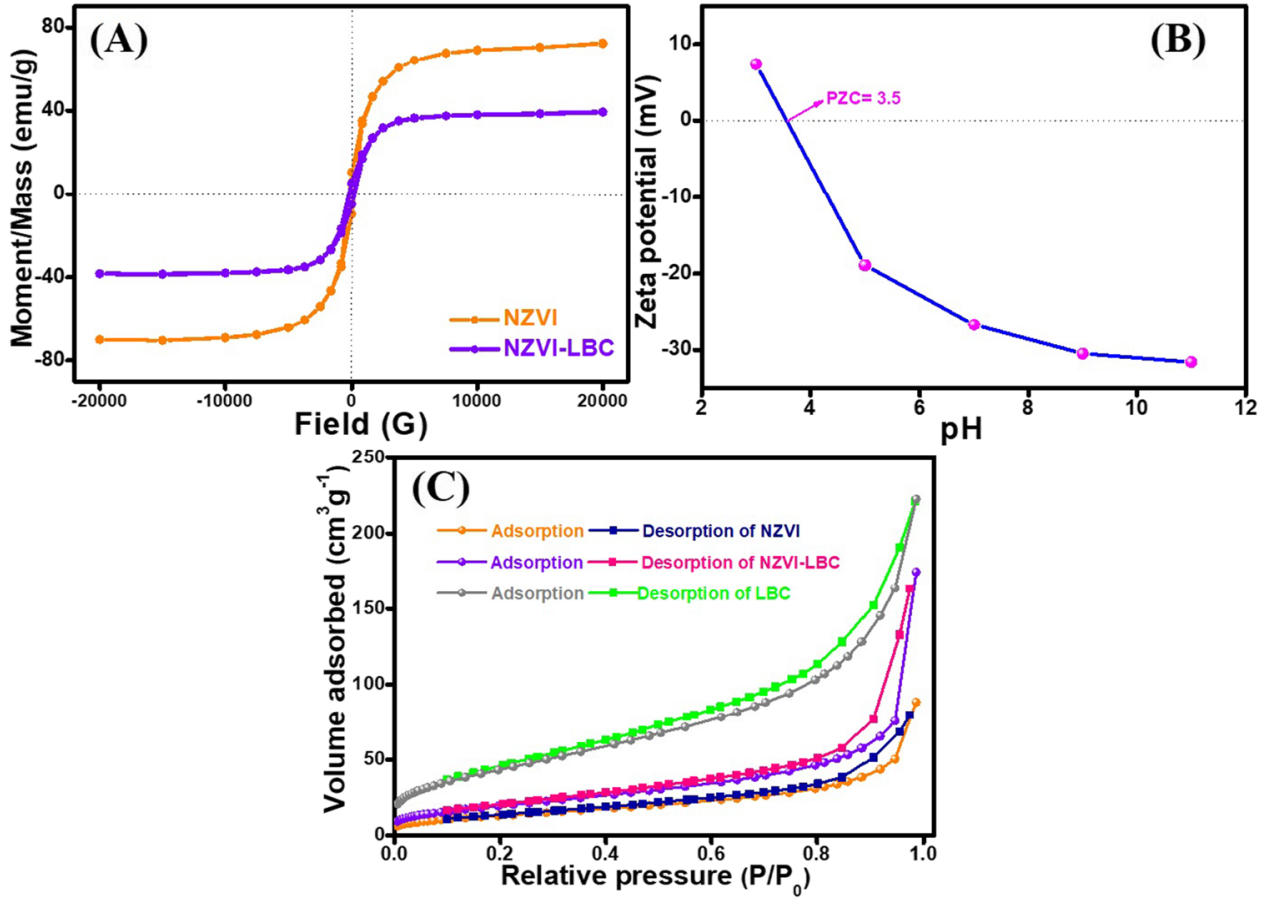
Fig. 5 Effect of $\mathrm{pH}(\mathbf{A})$, adsorbent dose $(\mathbf{B})$, initial concentration of $\mathrm{MB}(\mathbf{C})$, and temperature (D) on the MB uptake onto NZVI-LBC
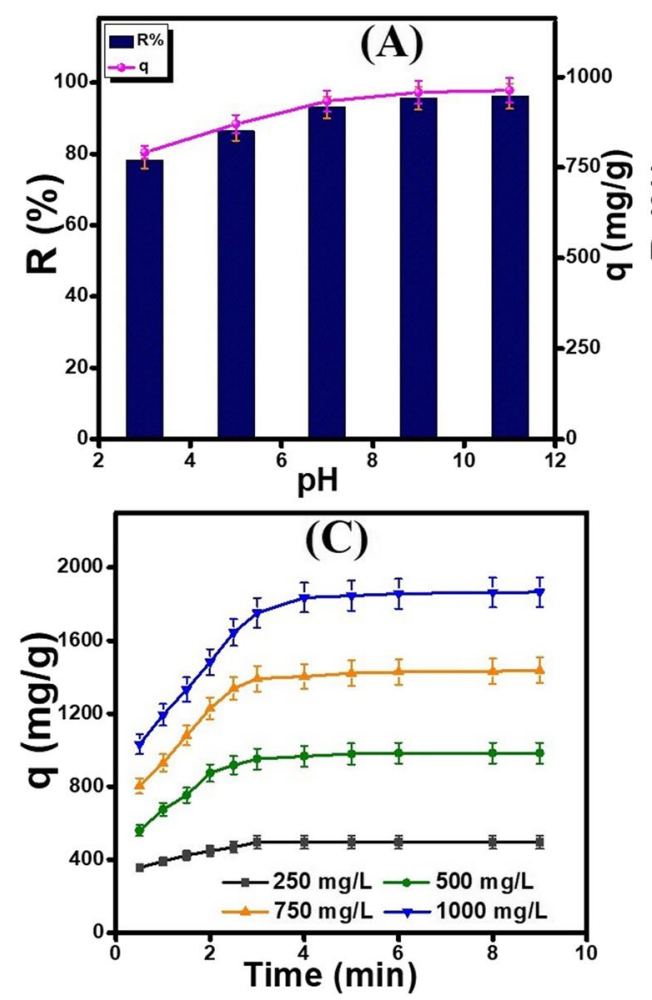
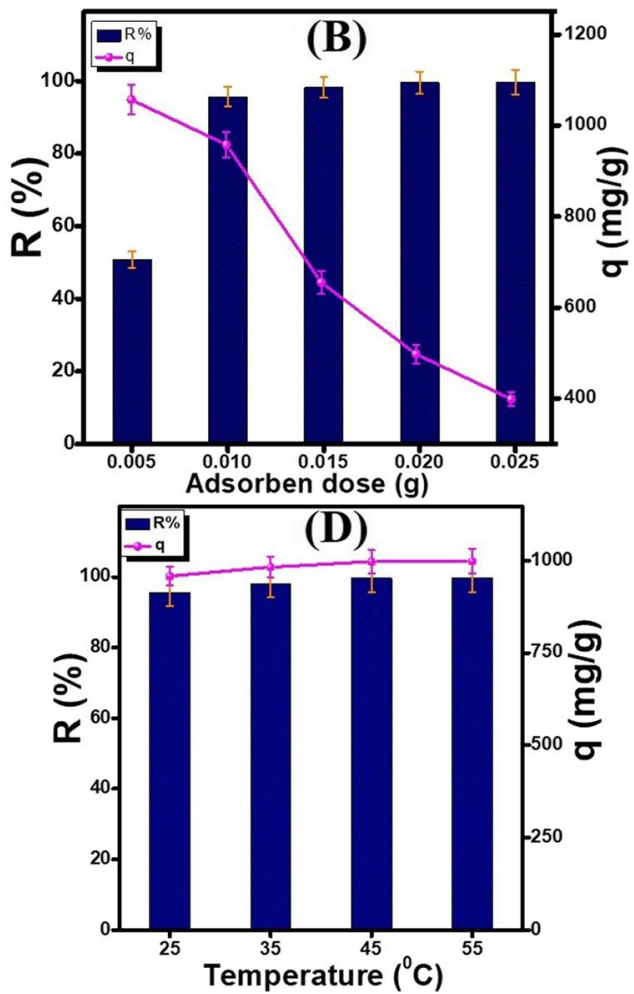

NZVI increases around two-fold after the incorporation into LBC since the $\mathrm{S}_{\mathrm{BET}}$ of NZVI, LBC, and NZVI-LBC are $79.51,217.58$, and $163.45 \mathrm{~m}^{2} / \mathrm{g}$, respectively. In addition to an enhancement in the pore volume of NZVI-LBC $(6.79 \mathrm{~nm})$ compared with the pure NZVI $(1.26 \mathrm{~nm})$ and LBC $(4.38 \mathrm{~nm})$.

\subsection{Investigation of the optimum conditions for the adsorption of MB onto NZVI-LBC nanocomposite}

A comparative study between the adsorption efficacy of LBC, NZVI, and NZVI-LBC was executed as follows: $10 \mathrm{mg}$ of each adsorbent was separately added to MB $(20 \mathrm{ml}$, $500 \mathrm{mg} / \mathrm{L}$ ) at $\mathrm{pH} 9$ and $25^{\circ} \mathrm{C}$. It was found that the adsorption capacity of MB onto LBC, NZVI, and NZVI-LBC were 49.36, 198.62, and $957.70 \mathrm{mg} / \mathrm{g}$, respectively. This finding clarified the fascinating impact of the mixing between NZVI and LBC to obtain an adsorbent with a propitious adsorbability toward such noxious dye.

\subsubsection{The influence of solution $\mathrm{pH}$}

The leverage of $\mathrm{pH}$ on the uptake efficacy of MB onto NZVILBC nanocomposite was thoroughly scrutinized over a wide $\mathrm{pH}$ range (3-11). Figure 5A depicts that the raising in $\mathrm{pH}$ from 3 to 11 dramatically enhances the adsorption capacity from 791.64 to $963.30 \mathrm{mg} / \mathrm{g}$ and the removal (\%) from 78.25 to $96.17 \%$. This finding may be anticipated by the significant competition between $\mathrm{H}^{+}$ions and the positive MB molecules towards NZVI-LBC at low $\mathrm{pH}$ that hinders the uptake of MB [51]. In addition, the NZVI-LBC surface is positively charged $(\mathrm{ZP}=7.4 \mathrm{mV})$ at low $\mathrm{pH}$, resulting in electrostatic repulsion forces between the cationic $\mathrm{MB}$ molecules and NZVI-LBC. Conversely, the raising in $\mathrm{pH}$ decreases the concentration of $\mathrm{H}^{+}$ions, as well as increases the negative charges on the surface of NZVI-LBC $(\mathrm{ZP}=-91.6 \mathrm{mV}$ at $\mathrm{pH}$ 11). Thence, the enhancement in the adsorption efficacy at high $\mathrm{pH}$ may be attributed to the strong electrostatic interaction between the positive MB molecules and the negatively charged NZVI-LBC nanocomposite [52, 53].

\subsubsection{The influence of dosage of NZVI-LBC nanocomposite}

Figure 5B outlines the influence of the augmentation of the dosage of NZVI-LBC on the adsorption capacity and removal (\%) of MB. It was noticed the increase in NZVI-LBC from 0.005 to $0.025 \mathrm{~g}$ declines the adsorption capacity of MB from 1057.09 to $398.76 \mathrm{mg} / \mathrm{g}$, respectively, which may be attributed to the aggregation of the particles. On the contrary, the increase in the dosage of NZVI-LBC uplifted the removal (\%) reached $99.68 \%$, resulting from the availability of severe binding sites [54]. However, the further rising in NZVI-LBC dose over $0.01 \mathrm{~g}$ has a slight effect on the removal (\%). Therefore, $0.01 \mathrm{~g}$ was picked out as the apt dose taking into 
Fig. 6 Kinetics models (A) and adsorption isotherms (B) of the MB uptake process onto NZVI-LBC
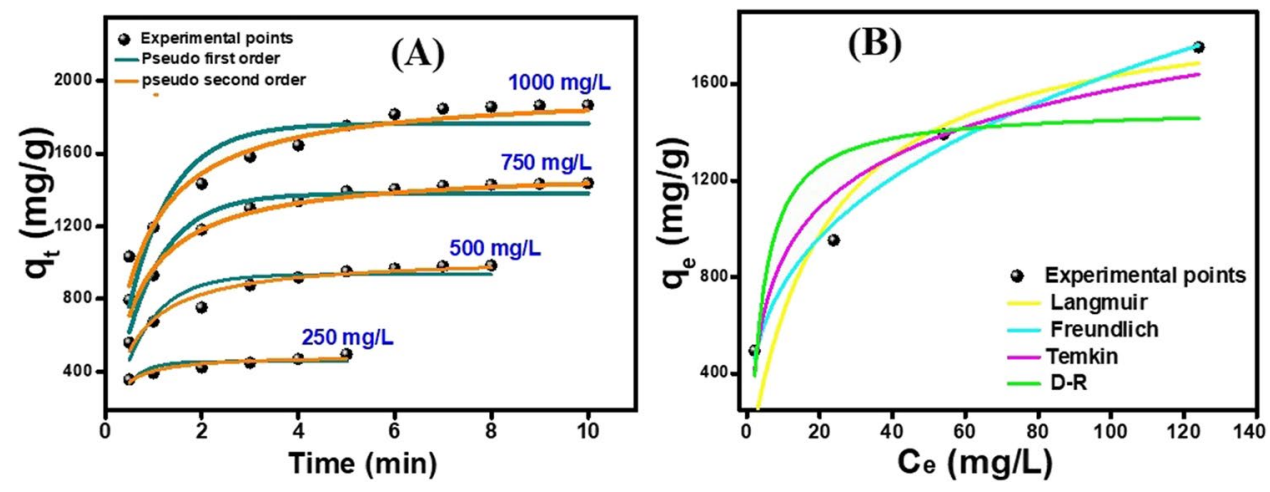

consideration adsorbent cost, removal rate, and adsorption amount.

\subsubsection{The influence of initial concentration of $M B$}

Figure 5C exhibits the leverage of the increase in the initial concentration of $\mathrm{MB}$ on the adsorption capacity of MB. It is obvious that NZVI-LBC nanocomposite provides extra-fast adsorption for $\mathrm{MB}$ at which the process reached equilibrium within $5 \mathrm{~min}$. Furthermore, there was a huge increase in the adsorption capacity of MB onto NZVI-LBC from 495.65 to $1864.41 \mathrm{mg} / \mathrm{g}$ with rising the initial concentration of MB from 250 to $1000 \mathrm{mg} / \mathrm{L}$, respectively. This behavior may be ascribed to the increment of the initial concentration of $\mathrm{MB}$ enhances its driving forces for surpassing the mass transfer resistance of MB molecules to reach NZVI-LBC surface $[55,56]$.

\subsubsection{The influence of temperature}

Figure 5D displays the process temperature effectiveness on the MB adsorption competence onto NZVI-LBC nanocomposite. It was monitored that the rising in temperature from 25 to $55^{\circ} \mathrm{C}$ slightly ameliorated the adsorption capacity and removal (\%) from $957.71 \mathrm{mg} / \mathrm{g}$ and $95.58 \%$ to $997.51 \mathrm{mg} / \mathrm{g}$ and $99.74 \%$, respectively. This result could be assigned to the increase in the system temperature leading to an increase in the motion of MB molecules towards the surface of the nanocomposite.

\subsection{Kinetic study}

To fully comprehend the MB uptake mechanism onto NZVILBC nanocomposite, the kinetic data were investigated by pseudo $1^{\text {st }}$ order and pseudo $2^{\text {nd }}$ order. The non-linear expressions of these used kinetic models are represented in Eqs. 3 and 4 [57]. Moreover, root mean square error (RMSE) test and chi-square $\left(\chi^{2}\right)$ test are calculated from Eqs. 5 and 6 $[58,59]$. $q_{t}=q_{e}\left(1-e^{-k_{1} t}\right)$

$\mathrm{q}_{t}=\frac{\mathrm{t} k_{2} q_{e}^{2}}{1+t k_{2} q_{e}}$

$\chi^{2}=\sum \frac{\left(q_{t}-q_{t m}\right)^{2}}{q_{t m}}$

$R M S E=\sqrt{ }\left(\frac{1}{N} \sum_{i=1}^{N}\left(q_{t m . i}-q_{t . i}\right)^{2}\right.$

where $k_{1}\left(\mathrm{~min}^{-1}\right)$ and $k_{2}\left(\mathrm{~g} \cdot \mathrm{mg}^{-1} \cdot \mathrm{min}^{-1}\right)$ denote the rate constant of pseudo $1^{\text {st }}$ order and pseudo $2^{\text {nd }}$ order, respectively. $q_{t}$ and $q_{e}$ are the adsorption capacity of MB at time $t$ and equilibrium, respectively. $q_{t m}$ and $q_{t}$ are the obtained adsorption capacity by using the model and the experimental data, respectively. $N$ is the number of experimental data and

Table 1 Kinetic parameters of the MB uptake onto NZVI-LBC nanocomposite

\begin{tabular}{|c|c|c|c|c|}
\hline \multirow[t]{2}{*}{ Kinetic models } & \multicolumn{4}{|c|}{ Concentration $(\mathrm{mg} / \mathrm{L})$} \\
\hline & 250 & 500 & 750 & 1000 \\
\hline $\begin{array}{l}\mathrm{q}_{\mathrm{e}, \exp }(\mathrm{mg} / \mathrm{g}) \\
\text { Pseudo } 1^{\text {st }} \text { order }\end{array}$ & \multicolumn{3}{|c|}{ Pseudo $1^{\text {st }}$ order } & 1864.4 \\
\hline $\mathrm{q}_{\mathrm{e}, \mathrm{cal}}(\mathrm{mg} / \mathrm{g})$ & 459.4 & 961.7 & 1414.2 & 2030.9 \\
\hline$k_{1}\left(\min ^{-1}\right)$ & 0.129 & 0.066 & 0.059 & 0.053 \\
\hline$R^{2}$ & 0.635 & 0.896 & 0.900 & 0.857 \\
\hline$\chi^{2}$ & 2.866 & 0.507 & 0.374 & 14.869 \\
\hline RMSE & 36.3 & 22.1 & 23.0 & 166.9 \\
\hline \multicolumn{5}{|l|}{ Pseudo $2^{\text {nd }}$ order } \\
\hline $\mathrm{q}_{\mathrm{e}, \mathrm{cal}}(\mathrm{mg} / \mathrm{g})$ & 503.9 & 989.3 & 1452.8 & 1826.3 \\
\hline$k_{2}\left(\mathrm{~g} \cdot \mathrm{mg}^{-1} \cdot \mathrm{min}^{-1}\right)$ & 0.0004 & 0.00008 & 0.00005 & 0.00004 \\
\hline$R^{2}$ & 0.870 & 0.960 & 0.945 & 0.940 \\
\hline$\chi^{2}$ & 0.135 & 0.030 & 0.167 & 0.778 \\
\hline RMSE & 8.2 & 5.5 & 15.6 & 38.1 \\
\hline
\end{tabular}


$q_{t m}$ and $q_{t}$ are the obtained adsorption capacity by using the model and the experimental data respectively.

The non-linear curves (Fig. 6A) and the reckoned kinetic parameters (Table1) clearly assert that the MB uptake process onto NZVI-LBC nanocomposite is well represented by pseudo $2^{\text {nd }}$ order at which its $R^{2}$ values are greater than those obtained from pseudo $1^{\text {st }}$ order. In addition, $\chi^{2}$ and RMSE values of pseudo $2^{\text {nd }}$ order are less than pseudo $1^{\text {st }}$ order as well as the convergence between $\mathrm{q}_{\exp }$ and $\mathrm{q}_{\mathrm{cal}}$ from pseudo $2^{\text {nd }}$ order, asserting the suitability of pseudo $2^{\text {nd }}$ order to represent the MB adsorption process [60, 61].

\subsection{Isotherm study}

To describe the kind of interaction between MB and NZVILBC nanocomposite, the equilibrium data were thoroughly fitted utilizing non-linear Langmuir, Freundlich, Temkin, and D-R Eqs. (7-11) [57].

Langmuir $; \mathrm{q}_{e}=\frac{q_{\max } K_{L} C_{e}}{1+K_{L} C_{e}}$

Freundlich; $q_{e}=k_{F} C_{e}^{1 / n}$

Temkin; $q_{e}=\frac{R T}{b_{T}} \ln k_{T} C_{e}$

$\mathrm{D}-\mathrm{R} ; q_{e}=q_{s} e^{-k_{D R} \varepsilon^{2}}$

$\varepsilon=R T \ln \left(1+\frac{1}{C_{e}}\right)$

where $q_{\max }$ denotes the maximum monolayer uptake and $k_{L}$ $(\mathrm{L} / \mathrm{mg})$ refers to Langmuir constant. $n$ and $k_{F}(\mathrm{~L} / \mathrm{mg})$ symbolize Freundlich constants. $R(8.314 \mathrm{~J} / \mathrm{mol} \mathrm{k})$ is the gas constant and $k_{T}(\mathrm{~L} / \mathrm{g})$ and $b_{T}(\mathrm{KJ} / \mathrm{mol})$ represent the equilibrium binding constant and Temkin constant, reprehensively. $q_{s}$ and $\varepsilon$ refer to the saturation capacity and the Polanyi potential, representatively. $K_{D R}\left(\mathrm{~mol}^{2} / \mathrm{K}^{2} \mathrm{~J}^{2}\right)$ expresses the average adsorption free energy of the adsorbate.

Figure 6B exhibits the non-linear curves of Langmuir, Freundlich, Temkin, and D-R models. It is evident from $R^{2}$ values (Table 2) that the MB uptake onto NZVI-LBC nanocomposite obeys Freundlich model. Besides, the reckoned $q_{\max }$ under Langmuir model was $1959.94 \mathrm{mg} / \mathrm{g}$. Moreover, the preference of the MB uptake process was proved via $n$ value since it was greater than 2 [62]. Furthermore, the computed bonding energy $\left(\mathrm{E}=1 /\left(2 \mathrm{~K}_{\mathrm{DR}}\right)^{1 / 2}\right)$ was $15.81 \mathrm{~kJ} /$ mol, suggesting that the adsorption of MB onto NZVI-LBC occurred via chemical bonds [63]. Importantly, NZVI-LBC nanocomposite possesses an extremely high adsorption
Table 2 Isotherms parameters for the MB uptake onto NZVI-LBC nanocomposite

\begin{tabular}{llc}
\hline Isotherm model & Parameter & Value \\
\hline Langmuir & $\mathrm{q}_{\max }(\mathrm{mg} / \mathrm{g})$ & 1959.9 \\
& $\mathrm{k}_{\mathrm{L}}(\mathrm{L} / \mathrm{mg})$ & 0.049 \\
& $R^{2}$ & 0.813 \\
& $\chi^{2}$ & 4.65 \\
Freundlich & $\mathrm{RMSE}$ & 95.5 \\
\multirow{3}{*}{ Temkin } & $\mathrm{n}$ & 3.03 \\
& $\mathrm{k}_{\mathrm{F}}(\mathrm{L} / \mathrm{mg})$ & 385.8 \\
& $\mathrm{R}^{2}$ & 0.985 \\
& $\mathrm{k}_{\mathrm{T}}(\mathrm{L} / \mathrm{g})$ & 1.83 \\
& $\mathrm{~b}_{\mathrm{T}}(\mathrm{KJ} / \mathrm{mol})$ & 0.082 \\
D-R & $R^{2}$ & 0.907 \\
& $\mathrm{q}_{\mathrm{s}}$ & 1500.4 \\
& $\mathrm{~K}_{\mathrm{DR}}\left(\mathrm{mol}^{2} / \mathrm{K}^{2} \mathrm{~J}^{2}\right)$ & 0.002 \\
& $R^{2}$ & 0.635 \\
\hline
\end{tabular}

Table 3 Comparison between the adsorption capacity of MB onto diversified reported adsorbents

\begin{tabular}{lll}
\hline Adsorbent & $\mathrm{q}_{\max }(\mathrm{mg} / \mathrm{g})$ & Reference \\
\hline $\mathrm{MnO}_{2}$-lignin BC composite & 248.96 & {$[64]$} \\
Wettorrefied microalgal BC & 129.57 & {$[65]$} \\
UiO-66/MIL-101(Fe)-GOCOOH com- & 448.70 & {$[80]$} \\
posite & & \\
Fe-AC composite & 357.10 & {$[66]$} \\
Persimmon fruit peel BC & 303.00 & {$[67]$} \\
Banana peel BC/iron oxide composite & 862.00 & {$[68]$} \\
NaOH/bamboo HC & 665.75 & {$[69]$} \\
Straw BC & 62.5 & {$[70]$} \\
NZVI & 208.33 & {$[71]$} \\
CNT-TA & 105 & {$[72]$} \\
MWCNT-SH & 10 & {$[73]$} \\
NZVI-BC & N/A & {$[74]$} \\
NZVI-LBC nanocomposite & 1959.94 & This study \\
\hline
\end{tabular}

capacity compared to other reported adsorbents in previous studies (Table 3 ).

\subsection{Selectivity study}

Actually, the real wastewater contains a plethora of dyes that violently vie for the active sites of the adsorbent and they might interact with each other as well. Consequently, it was crucial to assess the adsorption performance of the as-fabricated NZVI-LBC nanocomposite towards MB in the presence of interfering anionic dye (CR) and cationic dye (CV) in binary and ternary dye systems (Fig. 7A). It was recorded that the removal efficiency of MB in a MB single system, 
Fig. 7 Impact of interfering dyes on the removal (\%) of MB (A), recyclability of NZVI-LBC (B), XPS spectra of NZVI-LBC before and after the MB adsorption $(\mathbf{C})$ and FTIR spectra of NZVI-LBC before and after seven adsorption/desorption cycles of MB (D)
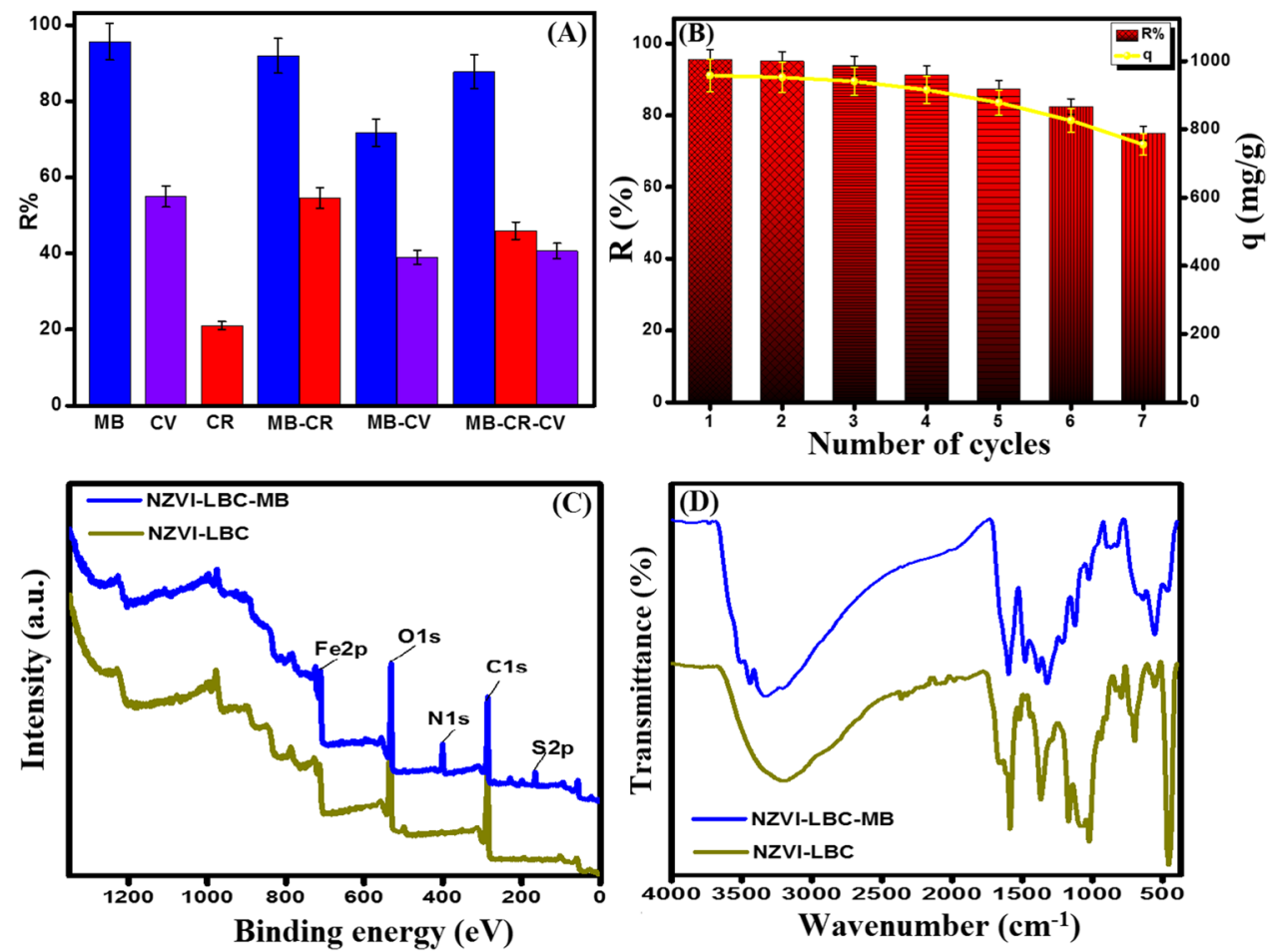

MB-CR and MB-CV binary systems, and MB-CR-CV ternary system were $95.58 \%, 91.91 \%, 71.73 \%$, and $87.72 \%$, respectively. There is a slight diminution in the removal (\%) of $\mathrm{MB}$ in the presence of $\mathrm{CR}$, reflecting the selectivity of NZVI-LBC towards MB. However, the removal (\%) of CR increased in a binary system (54.64\%) and ternary system $(49.95 \%)$ compared to a single one $(21.02 \%)$ which is most likely due to the interaction of CR with MB, agreeing with the previous study by Bentahar and his coworker [75]. In the case of the MB-CV binary system, it was monitored a significant decline in the removal (\%) of both $\mathrm{MB}$ and $\mathrm{CV}$ from 95.58 and $54.95 \%$ to 71.73 and $38.93 \%$, respectively, which may be attributed to the fierce competition occurs between the two cationic dyes for the active sites of NZVILBC nanocomposite.

\subsection{Reusability}

Undoubtedly the high magnetic property of NZVI-LBC nanocomposite provides easy and perfect separation, so the recyclability test was executed on NZVI-LBC for seven adsorption/desorption cycles of MB to confirm the importance of its magnetic property (Fig. 7B). An insignificant diminution was recorded after the 7th cycle in the adsorption capacity and removal (\%) from $957.71 \mathrm{mg} / \mathrm{g}$ and $95.58 \%$ to $755.52 \mathrm{mg} / \mathrm{g}$ to $75.01 \%$, respectively. This finding infers the great renewability of NZVI-LBC nanocomposite that renders it a viable candidate for the diverse potential applications.

\subsection{The postulated adsorption mechanism}

XPS spectrum of NZVI-LBC nanocomposite after the MB adsorption (Fig. 7C) elucidates the distinguishing peaks to $\mathrm{N}$ and $\mathrm{S}$ of $\mathrm{MB}$, asserting the successful uptake of $\mathrm{MB}$ onto NZVI-LBC. Furthermore, FTIR spectrum of NZVILBC after the adsorption process signifies the characteristic peaks of MB at 1124,1227 and $3436 \mathrm{~cm}^{-1}$ which are assigned to $\mathrm{C}-\mathrm{H}, \mathrm{C}-\mathrm{N}$ and $\mathrm{N}-\mathrm{H}$, respectively [76]. Owing to the ultra-high adsorption capacity of NZVI-LBC nanocomposite towards $\mathrm{MB}$, it was a pivotal issue to speculate how NZVI-LBC grasps the MB molecules from their solution. The results $\mathrm{ZP}$ and the experimental study of the impact of $\mathrm{pH}$ on the adsorption process attest that the electrostatic interaction mechanism dominants the adsorption process of the cationic MB onto the negatively charged NZVI-LBC. Furthermore, the possibility to reduce MB to its colorless form (leucomethylene blue; LMB) via the transferred electrons from $\mathrm{Fe}^{0}$ is one more hypothesis mechanism that was suggested in previous studies involving the adsorption of cationic dyes onto NZVI-LBC composites [77, 78]. The reduction of $\mathrm{MB}$ is clarified in the following equations:

$\mathrm{Fe}^{0} \rightarrow \mathrm{Fe}^{2+}+2 \mathrm{e}^{-}$

$\mathrm{MB}+\mathrm{ne}^{-} \rightarrow \mathrm{LMB}$

Besides, the complexation and flocculation may contribute to the adsorption of MB on NZVI-LBC since iron oxide/ 
Fig. 8 Possible mechanisms for the removal of MB onto NZVILBC

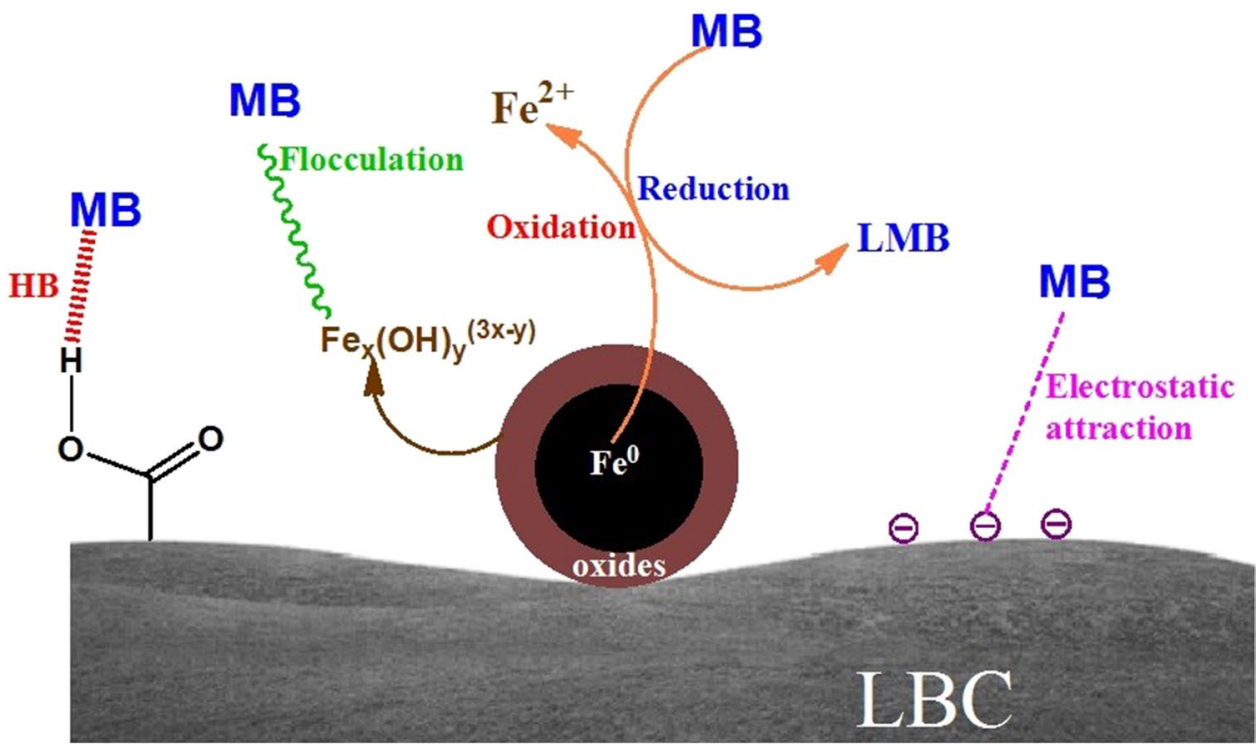

hydroxide might form a complex with MB and then may occur flocculation in the reaction solution as given in the following equation:

$\mathrm{MB}+\mathrm{nFe}_{\mathrm{x}}(\mathrm{OH})_{\mathrm{y}}^{(3 \mathrm{x}-\mathrm{y})} \rightarrow\left[\mathrm{MB}\left[\mathrm{Fe}_{\mathrm{x}}(\mathrm{OH})_{\mathrm{y}}^{(3 \mathrm{x}-\mathrm{y})}\right] \mathrm{n}\right]$

On the other hand, the structure nature of LBC vastly controls the $\mathrm{MB}$ uptake mechanism since the distributed $\mathrm{H}$ atoms on its surface may form $\mathrm{H}$-bonds with $\mathrm{N}$ atoms of MB. In addition, $n-\pi$ interaction via transfer the lone pairs of $\mathrm{O}$ atoms of $\mathrm{LBC}$ into $\pi$-orbital of $\mathrm{MB}$ aromatic ring $[51,79]$. Figure 8 represents the possible mechanisms for the removal of MB onto NZVI-LBC.

\section{Conclusion}

This work reported a successful synthesis of magnetic lemon-derived biochar (NZVI-LBC) for the adsorptive removal of MB. Results clarified the superior efficacy of the magnetic synthesized NZVI-LBC as a low-cost adsorbent that was examined for the first time as an adsorbent for the adsorptive removal of $\mathrm{MB}$. The adsorption process follows pseudo $2^{\text {nd }}$ order kinetic model with a good fitting to both Freundlich and Temkin isotherm models. The obtained NZVI-LBC is a highly effective adsorbent, much better than most reported biochars since the computed $\mathrm{q}_{\max }$ from Langmuir model was $1959.94 \mathrm{mg} / \mathrm{g}$ within incredibly short equilibrium time (5 min). Additionally, the reusability tests confirmed NZVI-LBC is magnetically separable and has good reusability. The results of this work indicate that green synthesis of biochar with magnetic property is an effective and economical route for the production of highly efficient, low-cost, and reusable adsorbents for the treatment of dye-pollutant water to minimize their environmental risks. This propitious adsorption behavior of NZVI-LBC nanocomposite towards MB may be due to the possibility to occur several adsorption mechanisms including electrostatic interaction, complexation, and flocculation, H-bonds, and $\mathrm{n}-\pi$ interaction. In addition to the de-colorization mechanism via reducing $\mathrm{MB}$ to the colorless $\mathrm{LMB}$, inspiring us with a new study involving determine the extent to which the decolorization mechanism affects the removal process.

Author contribution Eman Abd El-Monaem and Abdelazeem Eltaweil: Conceptualization, methodology, writing (review), formal analysis, and editing. Ahmed M. Omer: writing, review; editing. Gehan M. El-Subruiti and Mohy-Eldin: Review, editing, and supervision.

Funding Open access funding provided by The Science, Technology \& Innovation Funding Authority (STDF) in cooperation with The Egyptian Knowledge Bank (EKB).

Data availability The authors confirm that the data supporting the findings of this study are available within the article. Raw data supporting the findings of this study are available from the corresponding author upon reasonable request.

\section{Declarations}

Conflict of interest The authors declare no competing interests.

Open Access This article is licensed under a Creative Commons Attribution 4.0 International License, which permits use, sharing, adaptation, distribution and reproduction in any medium or format, as long as you give appropriate credit to the original author(s) and the source, provide a link to the Creative Commons licence, and indicate if changes were made. The images or other third party material in this article are included in the article's Creative Commons licence, unless indicated otherwise in a credit line to the material. If material is not included in the article's Creative Commons licence and your intended use is not 
permitted by statutory regulation or exceeds the permitted use, you will need to obtain permission directly from the copyright holder. To view a copy of this licence, visit http://creativecommons.org/licenses/by/4.0/.

\section{References}

1. Eltaweil AS, Omer AM, El-Aqapa HG, Gaber NM, Attia NF, ElSubruiti GM, Mohy-Eldin MS, Abd El-Monaem EM (2021) Chitosan based adsorbents for the removal of phosphate and nitrate: a critical review. Carbohydr Polym 274:118671

2. Omer AM, Dey R, Eltaweil AS, Abd El-Monaem EM, Ziora ZM (2022) Insights into recent advances of chitosan-based adsorbents for sustainable removal of heavy metals and anions. Arab J Chem $15: 103543$

3. Lv X, Xu J, Jiang G, Xu X (2011) Removal of chromium (VI) from wastewater by nanoscale zero-valent iron particles supported on multiwalled carbon nanotubes. Chemosphere 85:1204-1209

4. Hosny M, Eltaweil AS, Mostafa M, El-Badry YA, Hussein EE, Omer AM, Fawzy M (2022) Facile synthesis of gold nanoparticles for anticancer, antioxidant applications, and photocatalytic degradation of toxic organic pollutants. ACS Omega 7(3):3121-3133

5. Duman O, Polat TG, Diker CÖ, Tunç S (2020) Agar/א-carrageenan composite hydrogel adsorbent for the removal of methylene blue from water. Int J Biol Macromol 160:823-835

6. Eltaweil AS, Mamdouh IM, Abd El-Monaem EM, El-Subruiti GM (2021) Highly efficient removal for methylene blue and $\mathrm{Cu} 2+$ onto UiO-66 metal-organic framework/carboxylated graphene oxideincorporated sodium alginate beads. ACS Omega 6:23528-23541

7. Mashkoor F, Nasar A (2020) Magsorbents: Potential candidates in wastewater treatment technology-a review on the removal of methylene blue dye. J Magn Magn Mater 500:166408

8. Saha N, Das L, Das P, Bhowal A, Bhattacharjee C (2021) Comparative experimental and mathematical analysis on removal of dye using raw rice husk, rice husk charcoal and activated rice husk charcoal: batch, fixed-bed column, and mathematical modeling. Biomass Convers Biorefinery. https://doi.org/10.1007/ s13399-021-01996-8

9. Shu J, Liu R, Wu H, Liu Z, Sun X, Tao C (2018) Adsorption of methylene blue on modified electrolytic manganese residue: kinetics, isotherm, thermodynamics and mechanism analysis. J Taiwan Inst Chem Eng 82:351-359

10. El-Borady OM, Fawzy M, Hosny M (2021) Antioxidant, anticancer and enhanced photocatalytic potentials of gold nanoparticles biosynthesized by common reed leaf extract. Appl Nanosci: 1-12

11. Razavi-Khosroshahi H, Edalati K, Wu J, Nakashima Y, Arita M, Ikoma Y, Sadakiyo M, Inagaki Y, Staykov A, Yamauchi M (2017) High-pressure zinc oxide phase as visible-light-active photocatalyst with narrow band gap. J Mater Chem A 5:20298-20303

12. Hosny M, Fawzy M, El-Fakharany EM, Omer AM, Abd ElMonaem EM, Khalifa RE, Eltaweil AS (2022) Biogenic synthesis, characterization, antimicrobial, antioxidant, antidiabetic, and catalytic applications of platinum nanoparticles synthesized from Polygonum salicifolium leaves. J Environ Chem Eng 10:106806

13. Eltaweil AS, Fawzy M, Hosny M, Abd El-Monaem EM, Tamer TM, Omer AM (2022) Green synthesis of platinum nanoparticles using Atriplex halimus leaves for potential antimicrobial, antioxidant, and catalytic applications. Arab J Chem 15:103517

14. Moradi E, Ebrahimzadeh H, Mehrani Z, Asgharinezhad AA (2019) The efficient removal of methylene blue from water samples using three-dimensional poly (vinyl alcohol)/starch nanofiber membrane as a green nanosorbent. Environ Sci Pollut Res 26:35071-35081
15. Banerjee S, Benjwal P, Singh M, Kar KK (2018) Graphene oxide (rGO)-metal oxide ( $\mathrm{TiO} 2 / \mathrm{Fe} 3 \mathrm{O} 4)$ based nanocomposites for the removal of methylene blue. Appl Surf Sci 439:560-568

16. Eltaweil AS, Elgarhy GS, El-Subruiti GM, Omer AM (2020) carboxymethyl cellulose/carboxylated graphene oxide composite microbeads for efficient adsorption of cationic methylene blue dye. Int J Biol Macromol 154:307-318

17. Hosny M, Fawzy M, El-Borady OM, Mahmoud AED (2021) Comparative study between Phragmites australis root and rhizome extracts for mediating gold nanoparticles synthesis and their medical and environmental applications. Adv Powder Technol

18. Ibrahim M, Souleiman M, Salloum A (2021) Methylene blue dye adsorption onto activated carbon developed from Calicotome villosa via H3PO4 activation. Biomass Convers Biorefinery. https:// doi.org/10.1007/s13399-021-02027-2

19. Maroušek J, Kolář L, Strunecký O, Kopecký M, Bartoš P, Maroušková A, Cudlínová E, Konvalina P, Šoch M, Moudrý J $\mathrm{Jr}$ (2020) Modified biochars present an economic challenge to phosphate management in wastewater treatment plants. J Clean Prod 272:123015

20. Rumjit NP, Samsudin NA, Low FW, Thomas P, Lai CW, Chellam PV, Johan MRB, Lim Y-C, Amin N, Tiong SK (2021) Kinetic and isotherm studies on adsorptive removal of sulfates by cotton shell derived biochar: Recovery of sulfates from marcasite soil. Sustain Chem Pharm 20:100361

21. Subratti A, Vidal JL, Lalgee LJ, Kerton FM, Jalsa NK (2021) Preparation and characterization of biochar derived from the fruit seed of Cedrela odorata $L$ and evaluation of its adsorption capacity with methylene blue. Sustain Chem Pharm 21:100421

22. Mahmoud ME, El-Ghanam AM, Saad SR, Mohamed RHA (2020) Promoted removal of metformin hydrochloride anti-diabetic drug from water by fabricated and modified nanobiochar from artichoke leaves. Sustain Chem Pharm 18:100336

23. Kaçakgil EC, Çetintaş S (2021) Preparation and characterization of a novel functionalized agricultural waste-based adsorbent for $\mathrm{Cu} 2+$ removal: evaluation of adsorption performance using response surface methodology. Sustain Chem Pharm 22:100468

24. Nguyen V-T, Nguyen T-B, Huang C, Chen C-W, Bui X-T, Dong C-D (2021) Alkaline modified biochar derived from spent coffee ground for removal of tetracycline from aqueous solutions. J Water Process Eng 40:101908

25. Kang J-K, Seo E-J, Lee C-G, Moon J-K, Park SJ (2021) Effectivity and adsorption mechanism of food waste biochar for triclosan removal: a spectroscopic and experimental approach. Biomass Convers Biorefinery. https://doi.org/10.1007/s13399-021-01997-7

26. Attia NF, Park J, Oh H (2018) Facile tool for green synthesis of graphene sheets and their smart free-standing UV protective film. Appl Surf Sci 458:425-430

27. Jung M, Park J, Lee K, Attia NF, Oh H (2020) Effective synthesis route of renewable nanoporous carbon adsorbent for high energy gas storage and CO2/N2 selectivity. Renew Energy 161:30-42

28. El-Maghrabi N, El-Borady OM, Hosny M, Fawzy M (2021) Catalytic and Medical Potential of a Phyto-Functionalized Reduced Graphene Oxide-Gold Nanocomposite Using Willow-Leaved Knotgrass. ACS Omega 6(50):34954-34966

29. Khan N, Chowdhary P, Ahmad A, Giri BS, Chaturvedi P (2020) Hydrothermal liquefaction of rice husk and cow dung in MixedBed-Rotating Pyrolyzer and application of biochar for dye removal. Bioresour Technol 309:123294

30. Shu Y, Ji B, Cui B, Shi Y, Wang J, Hu M, Luo S, Guo D (2020) Almond shell-derived, biochar-supported, nano-zero-valent iron composite for aqueous hexavalent chromium removal: performance and mechanisms. Nanomaterials 10:198

31. Abdelfatah AM, Fawzy M, El-Khouly ME, Eltaweil AS (2021) Efficient adsorptive removal of tetracycline from aqueous solution 
using phytosynthesized nano-zero valent iron. J Saudi Chem Soc 25:101365

32. Wang S, Zhao M, Zhou M, Li YC, Wang J, Gao B, Sato S, Feng K, Yin W, Igalavithana AD (2019) Biochar-supported nZVI (nZVI/BC) for contaminant removal from soil and water: a critical review. J Hazard Mater 373:820-834

33. He F, Zhao D, Liu J, Roberts CB (2007) Stabilization of Fe- Pd nanoparticles with sodium carboxymethyl cellulose for enhanced transport and dechlorination of trichloroethylene in soil and groundwater. Ind Eng Chem Res 46:29-34

34. Hussain I, Li M, Zhang Y, Li Y, Huang S, Du X, Liu G, Hayat W, Anwar N (2017) Insights into the mechanism of persulfate activation with nZVI/BC nanocomposite for the degradation of nonylphenol. Chem Eng J 311:163-172

35. Iqbal J, Shah NS, Sayed M, Niazi NK, Imran M, Khan JA, Khan ZUH, Hussien AGS, Polychronopoulou K, Howari F (2021) Nano-zerovalent manganese/biochar composite for the adsorptive and oxidative removal of Congo-red dye from aqueous solutions. J Hazard Mater 403:123854

36. Wang C, Huang R, Sun R (2020) Green one-spot synthesis of hydrochar supported zero-valent iron for heterogeneous Fentonlike discoloration of dyes at neutral pH. J Mol Liq 320:114421

37. Mishra S, Yadav SS, Rawat S, Singh J, Koduru JR (2019) Corn husk derived magnetized activated carbon for the removal of phenol and para-nitrophenol from aqueous solution: Interaction mechanism, insights on adsorbent characteristics, and isothermal, kinetic and thermodynamic properties. J Environ Manage 246:362-373

38. Lingamdinne LP, Choi J-S, Angaru GKR, Karri RR, Yang J-K, Chang Y-Y, Koduru JR (2022) Magnetic-watermelon rinds biochar for uranium-contaminated water treatment using an electromagnetic semi-batch column with removal mechanistic investigations. Chemosphere 286:131776

39. Liu L, Liu X, Wang D, Lin H, Huang L (2020) Removal and reduction of $\mathrm{Cr}(\mathrm{VI})$ in simulated wastewater using magnetic biochar prepared by co-pyrolysis of nano-zero-valent iron and sewage sludge. J Clean Prod 257:120562

40. Eltaweil AS, El-Tawil AM, Abd El-Monaem EM, El-Subruiti GM (2021) Zero valent iron nanoparticle-loaded nanobentonite intercalated carboxymethyl chitosan for efficient removal of both anionic and cationic dyes. ACS Omega 6:6348-6360

41. El Bestawy E, El-Shatby BF, Eltaweil AS (2020) Integration between bacterial consortium and magnetite ( $\mathrm{Fe} 3 \mathrm{O} 4$ ) nanoparticles for the treatment of oily industrial wastewater. World J Microbiol Biotechnol 36:1-16

42. Eltaweil A, Mohamed HA, Abd El-Monaem EM, El-Subruiti G (2020) Mesoporous magnetic biochar composite for enhanced adsorption of malachite green dye: Characterization, adsorption kinetics, thermodynamics and isotherms. Adv Powder Technol 31:1253-1263

43. Li Z, Liu D, Huang W, Wei X, Huang W (2020) Biochar supported $\mathrm{CuO}$ composites used as an efficient peroxymonosulfate activator for highly saline organic wastewater treatment. Sci Total Environ $721: 137764$

44. Vo AT, Nguyen VP, Ouakouak A, Nieva A, Doma BT, Tran HN, Chao H-P (2019) Efficient removal of Cr (VI) from water by biochar and activated carbon prepared through hydrothermal carbonization and pyrolysis: adsorption-coupled reduction mechanism. Water 11:1164

45. Wei D, Li B, Luo L, Zheng Y, Huang L, Zhang J, Yang Y, Huang $H$ (2020) Simultaneous adsorption and oxidation of antimonite onto nano zero-valent iron sludge-based biochar: Indispensable role of reactive oxygen species and redox-active moieties. J Hazard Mater 391:122057

46. Toto NA, Elhenawy HI, Eltaweil AS, El-Ashram S, El-Samad LM, Moussian B, El Wakil A (2022) Musca domestica (Diptera:
Muscidae) as a biological model for the assessment of magnetite nanoparticles toxicity. Sci Total Environ 806:151483

47. Mitzia A, Vítková M, Komárek M (2020) Assessment of biochar and/or nano zero-valent iron for the stabilisation of $\mathrm{Zn}, \mathrm{Pb}$ and $\mathrm{Cd}$ : A temporal study of solid phase geochemistry under changing soil conditions. Chemosphere 242:125248

48. Zhang Q, Wang Y, Wang Z, Zhang Z, Wang X, Yang Z (2021) Active biochar support nano zero-valent iron for efficient removal of U (VI) from sewage water. J Alloys Compd 852:156993

49. Ye S, Cheng M, Zeng G, Tan X, Wu H, Liang J, Shen M, Song B, Liu J, Yang H (2020) Insights into catalytic removal and separation of attached metals from natural-aged microplastics by magnetic biochar activating oxidation process. Water Res 179:115876

50. Zhu K, Chen C (2019) Application of nZVI and its composites into the treatment of toxic/radioactive metal ions. Interface Science and Technology. Elsevier 29:330-287

51. Fan S, Wang Y, Wang Z, Tang J, Tang J, Li X (2017) Removal of methylene blue from aqueous solution by sewage sludge-derived biochar: Adsorption kinetics, equilibrium, thermodynamics and mechanism, Journal of Environmental. Chem Eng 5:601-611

52. Yalvaç G, Bayrak B (2020) Use of natural and effective mandarin peel in elimination of malachite green from the aqueous media: Adsorption properties, kinetics and thermodynamics. Desalination Water Treat 177:176

53. Yildırım GM, Bayrak B (2021) The synthesis of biochar-supported nano zero-valent iron composite and its adsorption performance in removal of malachite green. Biomass Convers Biorefinery. https://doi.org/10.1007/s13399-021-01501-1

54. Shittu I, Edathil AA, Alsaeedi A, Al-Asheh S, Polychronopoulou K, Banat F (2019) Development of novel surfactant functionalized porous graphitic carbon as an efficient adsorbent for the removal of methylene blue dye from aqueous solutions, Journal of Water. Process Eng 28:69-81

55. Temel F, Turkyilmaz M, Kucukcongar S (2020) Removal of methylene blue from aqueous solutions by silica gel supported calix [4] arene cage: investigation of adsorption properties. Eur Polym J 125:109540

56. Somsesta N, Sricharoenchaikul V, Aht-Ong D (2020) Adsorption removal of methylene blue onto activated carbon/cellulose biocomposite films: equilibrium and kinetic studies. Mater Chem Phys 240:122221

57. Ahamad K, Singh R, Baruah I, Choudhury H, Sharma M (2018) Equilibrium and kinetics modeling of fluoride adsorption onto activated alumina, alum and brick powder, Groundwater for. Sustain Dev 7:452-458

58. Goel J, Kadirvelu K, Rajagopal C, Garg VK (2005) Removal of lead (II) by adsorption using treated granular activated carbon: batch and column studies. J Hazard Mater 125:211-220

59. Maliyekkal SM, Shukla S, Philip L, Nambi IM (2008) Enhanced fluoride removal from drinking water by magnesia-amended activated alumina granules. Chem Eng J 140:183-192

60. Wang Y, Zeng D, Dai Y, Fang C, Han X, Zhang Z, Cao X, Liu Y (2020) The adsorptive ability of 3D flower-like titanium phosphate for U (VI) in aqueous solution. Water Air Soil Pollut 231:1-12

61. Omer AM, El-Monaem A, Eman M, El-Subruiti GM, El-Latif A, Mona M, Eltaweil AS (2021) Fabrication of easy separable and reusable MIL-125 (Ti)/MIL-53 (Fe) binary MOF/CNT/Alginate composite microbeads for tetracycline removal from water bodies. Sci Rep 11:1-14

62. Ouasfi N, Zbair M, Bouzikri S, Anfar Z, Bensitel M, Ahsaine HA, Sabbar E, Khamliche L (2019) Selected pharmaceuticals removal using algae derived porous carbon: experimental, modeling and DFT theoretical insights. RSC Adv 9:9792-9808

63. Devi AP, Mishra PM (2019) Biosorption of dysprosium (III) using raw and surface-modified bark powder of Mangifera indica: 
isotherm, kinetic and thermodynamic studies. Environ Sci Pollut Res 26:6545-6556

64. Liu X-J, Li M-F, Singh SK (2021) Manganese-modified lignin biochar as adsorbent for removal of methylene blue. J Market Res 12:1434-1445

65. Yu KL, Lee XJ, Ong HC, Chen W-H, Chang J-S, Lin C-S, Show PL, Ling TC (2021) Adsorptive removal of cationic methylene blue and anionic Congo red dyes using wet-torrefied microalgal biochar: Equilibrium, kinetic and mechanism modeling. Environ Pollut 272:115986

66. Altıntıg E, Altundag H, Tuzen M, Sar1 A (2017) Effective removal of methylene blue from aqueous solutions using magnetic loaded activated carbon as novel adsorbent. Chem Eng Res Des 122:151-163

67. Ates A, Oymak T (2020) Characterization of persimmon fruit peel and its biochar for removal of methylene blue from aqueous solutions: thermodynamic, kinetic and isotherm studies. Int J Phytorem 22:607-616

68. Zhang P, O'Connor D, Wang Y, Jiang L, Xia T, Wang L, Tsang DC, Ok YS, Hou D (2020) A green biochar/iron oxide composite for methylene blue removal. J Hazard Mater 384:121286

69. Qian W-C, Luo X-P, Wang X, Guo M, Li B (2018) Removal of methylene blue from aqueous solution by modified bamboo hydrochar. Ecotoxicol Environ Saf 157:300-306

70. Li G, Zhu W, Zhang C, Zhang S, Liu L, Zhu L, Zhao W (2016) Effect of a magnetic field on the adsorptive removal of methylene blue onto wheat straw biochar. Biores Technol 206:16-22

71. Arabi S, Sohrabi MR (2014) Removal of methylene blue, a basic dye, from aqueous solutions using nano-zerovalent iron. Water Sci Technol 70:24-31

72. Gan D, Liu M, Huang H, Chen J, Dou J, Wen Y, Huang Q, Yang Z, Zhang X, Wei Y (2018) Facile preparation of functionalized carbon nanotubes with tannins through mussel-inspired chemistry and their application in removal of methylene blue. J Mol Liq 271:246-253

73. Robati D, Mirza B, Ghazisaeidi R, Rajabi M, Moradi O, Tyagi I, Agarwal S, Gupta VK (2016) Adsorption behavior of methylene blue dye on nanocomposite multi-walled carbon nanotube functionalized thiol (MWCNT-SH) as new adsorbent. J Mol Liq 216:830-835

74. Zhou Y, Gao B, Zimmerman AR, Chen H, Zhang M, Cao X (2014) Biochar-supported zerovalent iron for removal of various contaminants from aqueous solutions. Biores Technol 152:538-542

75. Bentahar S, Dbik A, El Khomri M, El Messaoudi N, Lacherai A (2017) Adsorption of methylene blue, crystal violet and congo red from binary and ternary systems with natural clay: Kinetic, isotherm, and thermodynamic, Journal of Environmental. Chem Eng 5:5921-5932

76. Alshehri AA, Malik MA (2019) Biogenic fabrication of $\mathrm{ZnO}$ nanoparticles using Trigonella foenum-graecum (Fenugreek) for proficient photocatalytic degradation of methylene blue under UV irradiation. J Mater Sci: Mater Electron 30:16156-16173

77. Elkady M, Shokry H, El-Sharkawy A, El-Subruiti G, Hamad $\mathrm{H}$ (2019) New insights into the activity of green supported nanoscale zero-valent iron composites for enhanced acid blue- 25 dye synergistic decolorization from aqueous medium. J Mol Liq 294:111628

78. Trinh B-S, Le PT, Werner D, Phuong NH, Luu TL (2019) Rice husk biochars modified with magnetized iron oxides and nano zero valent iron for decolorization of dyeing wastewater. Processes $7: 660$

79. Li H, Liu L, Cui J, Cui J, Wang F, Zhang F (2020) High-efficiency adsorption and regeneration of methylene blue and aniline onto activated carbon from waste edible fungus residue and its possible mechanism. RSC Adv 10:14262-14273

80. Eltaweil AS, Abd El-Monaem EM, El-Subruiti GM, Abd El-Latif MM, Omer AM (2020) Fabrication of UiO-66/MIL-101 (Fe) binary $\mathrm{MOF} /$ carboxylated-GO composite for adsorptive removal of methylene blue dye from aqueous solutions. RSC Advances. 10(32):19008-19019

Publisher's note Springer Nature remains neutral with regard to jurisdictional claims in published maps and institutional affiliations. 